\title{
DAKWAH DAN ISLAM FUNDAMENTALIS
}

\author{
Sudir Koadhi \\ Unismu Makassar \\ e-mail:konawe07@gmail.com
}

\begin{abstract}
The term fundamentalism was initially used only to refer to Catholics who rejected modernity and maintained the teachings of religious orthodoxy. However, at present, the term is also used for adherents of other religions which have similarities so there are also Islamic, Hindu and Buddhist fundamentalism. Over time, the use of the term fundamentalism raises certain images, such as extremism, fanaticism, or even terrorism in maintaining religious beliefs. The Islamic fundamentalist movement in Indonesia is more influenced by domestic and foreign social-political instability, from the Dutch colonial era until the end of the Suharto government. The era of reform, freedom of opinion and groups, is a moment for fundamentalists to voice their opinions, offer solutions to overcome the multidimensional crisis that occurred in Indonesia. Therefore, the propaganda of wisdom, advice, and dialogue must continue to be established with the fundamental groups of Islam to straighten out some of them have come out of the rules of Amar makruf nahimungkar. Advice and dialogue must continue to be made for them to improve the shortcomings.
\end{abstract}

\section{Key Words:}

Da'wah, Fundamentalism, Islam 


\begin{abstract}
Abstrak
Istilah fundamentalisme pada awalnya digunakan hanya untuk menyebut penganut Katolik yang menolak modernitas dan mempertahankan ajaran ortodoksi agamanya. Namun, saat ini, istilah itu juga digunakan untuk penganut agama-agama lainnya yang memiliki kemiripan sehingga ada juga fundamentalisme Islam, Hindu, dan Budha. Seiring waktu, penggunaan istilah fundamentalisme menimbulkan citra tertentu, misalnya ekstrimisme, fanatisme, atau bahkan terorisme dalam mempertahankan keyakinan keagamaan. Gerakan fundamentalis Islam di Indonesia lebih banyak dipengaruhi oleh instabilitas sosial politik dalam dan luar negeri, mulai jaman penjajahan Belanda sampai akhir masa pemerintahan Suharto. Era reformasi, kebebasan berpendapat dan berkelompok, merupakan momen bagi kaum fundamentalis untuk menyuarakan pendapatnya, menawarkan solusi mengatasi krisis multidimensi yang terjadi di Indonesia. Oleh karena itu, dakwah bi al hikmah, nasehat, dan dialog harus terus dijalin dengan kelompok fundamental Islam untuk meluruskan sebagian dari mereka telah keluar dari ramburambu amar makruf nahi mungkar. Nasehat dan dialog harus terus dijalin kepada mereka agar memperbaiki kekurangankekurangan yang ada.
\end{abstract}

Kata Kunci:

Dakwah, Fundamentalisme, Islam 


\section{A. Pendahuluan}

Sejak kejatuhan Khilafah Usmani pada tahun 192430, setiap kelompok masyarakat yang bergama Islam seolah-olah berlomba untuk membangkitkan kembali Islam dari keterpurukan yang dideritanya, terutama keterpurukan yang diakibatkan oleh imperalisme Barat. Konsekuensi logis dari usaha membangkitkan Islam tersebut berwujud dalam bentuk dedikasi Islam (Islamic dedication).

Di Indonesia, dedikasi Islam dapat dilihat dari ramainya kelas menengah kota yang berduyun-duyun melaksanakan ajaran agama. Pada saat bulan Ramadhan, peningkatan dedikasi terhadap Islam itu begitu terasa. Televisi, hotel, dan perkantoran diramaikan dengan suasana suci bulan Ramadhan. Dedikasi Islam menjadi fenomena menarik karena terjadi pada saat banyak kalangan memprediksi bahwa kekuatan rasional dari sains dan teknologi telah berhasil menepikan misteri spiritual dari kerangka berpikir manusia modern. Dalam hal ini, manusia modern menyangka bahwa kecukupan materi dapat memenuhi kebahagiaan manusia. Pada saat itulah, justru dedikasi Islam mendapat moment umumnya. ${ }^{31}$

Sebagian kalangan menyebut dedikasi Islam ini sebagai kebangkitan (revival), tapi sebagian lainnya menyebutnya dengan penemuan kembali (rediscovery). ${ }^{32}$ Salah satu yang menonjol dan fenomena kebangkitan agama tersebut adalah

\footnotetext{
${ }^{30}$ Ali Muhammad al-Salabi, Al-Daulah al-Usmaniyahyyah; 'Awamil al-Nahdah wa Asbab al Sukut. Teri. Samson Rahman, Bangkit dan Runtuhnya Khilafah Utsmaniyah (Cet. IV; Jakarta: Pustaka alKautsar, 2011 ), xv.

31 Jamhari dan Jajang Jahroni, Gerakan Salafi Radikal di Indonesia (Jakarta: Raja Grafindo Persada, 2004), $11-12$.

32 Robert Wuthnow, Meaning and Moral Order (California: The University of California Press, 1987), $1-5$.
} 
menguatnya pemahaman Islam yang fundamentalis. Dan fenomena fundamentalis ini dialami oleh semua agama di hampir seluruh tempat di dunia ini. ${ }^{33}$

Istilah fundamentalis ini muncul pertama kali di lingkungan agama Nasrani khususnya di Amerika Serikat, menunjuk kepada bentuk-bentuk konservatif protestanisme, yang biasanya anti kepada kaum modernis dengan interpretasi yang agak literal dan terbatas terhadap kitab Injil dan sangat menekankan etika tradisional Kristen. Akan tetapi, istilah ini sekarang menjadi ikon tersendiri bagi kelompok-kelompok Islam konservatif dan sering diposisikan dan disifati dengan hal-hal yang berbau pejoratif (bersifat merendahkan). Mereka dianggap sebagai kelompok pembangkang, banyak melakukan tindak kekerasan seperti melakukan teror, intimidasi, bahkan pembunuhan dalam mencapai tujuannya. Oleh karenanya, tidak sedikit kalangan umat Islam yang merasa keberatan untuk memberikan sifat "fundamentalis" ke dalam Islam. Hal itu mengingat ajaran Islam yang diturunkan kepada Nabi Muhammad sallallahu 'alaihi wasallam membawa misi kedamaian, keselamatan dan rahmat bagi seluruh alam (rahmatan lil'alamin).

Namun demikian, Islam fundamentalis itu jelas adanya. Ada orang-orang beragama Islam yang sedemikian fanatiknya dalam memegangi ajaran agama sampai-sampai tidak tersedia ruang bagi penafsiran atau pemahaman baru. Mereka menganggap salah orang yang tidak bersikap demikian kepada ajaran agamanya. Bahkan, ada yang melangkah lebih jauh lagi dengan melakukan tindakan- tindakan

\footnotetext{
33 Jamhari dan Jajang Jahroni, Gerakan Salafi, 12.
} 
yang merugikan orang lain dan mengganggu ketentraman masyarakat atas nama agama. $^{34}$

Oleh sebab itu, dalam tulisan sederhana ini penulis akan mengkaji apa yang dimaksud dengan Islam Fundamental, karakteristik paham Islam fundamentalis, latar belakang timbulnya fundamentalisme dalam Islam, gerakan Islam fundamentalis di Indonesia, dan dakwah dan sikap terhadap Islam fundamentalis.

\section{B. Islam Fundamentalis}

Istilah fundamentalis muncul pertama kali di kalangan agama Kristen Amerika Serikat, dan baru ditemukan dalam berbagai kamus dan ensiklopedia pada tahun 1960-an. Dalam terbitan tahun 1966, Kamus Kecil Petite Larousse Encyclopedique, memuat istilah fundamentalis dengan pengertian yang sangat umum, yaitu "Sikap orang-orang yang menolak penyesuaian kepercayaan dengan kondisi-kondisi modern". Sementara dalam Kamus Saku Grand Larousse Encyclopedique yang terbit tahun 1979 memuatnya dengan hanya mengaitkannya dengan agama katolik saja, yakni "kondisi-kondisi pemikiran di kalangan sebagian penganut Katolik yang menolak penyesuaian dengan kondisi kehidupan modern".

Kamus Grand Larousse Encyclopedique yang terbit pada tahun 1984 menyebutkannya secara lebih komprehensif, yaitu "Inti gerakan keagamaan (fundamentalisme) adalah sikap statis yang menentang segala bentuk perkembangan dan perubahan". Masih dalam Kamus Grand Larousse Encyclopedique yang merupakan kamus untuk perguruan tinggi, terbitan tahun

\footnotetext{
${ }^{34}$ Machasin, "Fundamentalis dan Terorisme", dalam Negara Tuhan; The Thematic Encyclopedia (Jakarta: SR Ins Publishing, 2004), 793.
} 
1987 memberikan defenisi dengan; "(Fundamentalisme) adalah sikap sementara penganut Katolik yang menentang semua bentuk pembaharuan saat mereka menyatakan keterkaitan mereka dengan warisan lama". ${ }^{35}$

Istilah fundamentalisme pada mulanya dipakai untuk menyebut gerakan dalam agama Kristen Protestan di Amerika Serikat, yang menganut ajaran ortodoksi Kristen yang berdasarkan atas keyakinan-keyakinan mendasar tertentu. Keyakinankeyakinan tersebut adalah:

1. The literal inerrancy of the Scriptures (Kitab Suci secara harfiah sama sekali tidak mengandung kesalahan);

2. The second coming of Jesus Christ (Yesus akan turun kembali ke dunia);

3. The virgin birth (Yesus dilahirkan dari perawan Maria, bukan dari konsepsi tak ternoda atau immaculate conception);

4. The physical resurrection of the body (Yesus dibangkitkan secara jasmaniyah dari kematian);

5. The substitutionary atonement (Yesus menebus dosa seluruh manusia). ${ }^{36}$

Istilah fundamentalisme yang pada awalnya digunakan hanya untuk menyebut penganut Katolik yang menolak modernitas dan mempertahankan ajaran ortodoksi agamanya. Namun, saat ini, istilah itu juga digunakan untuk penganut agamaagama lainnya yang memiliki kemiripan sehingga ada juga fundamentalisme Islam, Hindu, dan Budha. Sejalan dengan itu, penggunaan istilah fundamentalisme

\footnotetext{
${ }^{35}$ R. Garaudy, Islam Fundamentalis dan Fundamentalis lainnya.Teri: Afif Muhammad (Bandung: Penerbit Pustaka, 1993), 3. 117.

${ }^{36}$ Frederick M. Denny, Islam and The Muslim Community (New York: Herper \& Row, 1987),
} 
menimbulkan citra tertentu, misalnya ekstrimisme, fanatisme, atau bahkan terorisme dalam mewujudkan atau mempertahankan keyakinan keagamaan.

Mereka yang disebut kaum fundamentalis sering disebut sebagai tidak rasional, tidak moderat, dan cenderung melakukan tindakan kekerasan jika perlu. Sementara itu, menurut M. Said al-Asymawi, fundamentalisme itu sebenarnya tidak selalu berkonotasi negatif, sejauh gerakan itu bersifat rasional dan spiritual. Artinya, memahami ajaran agama berdasarkan semangat dan konteksnya sebagaimana ditunjukkan oleh fundamentalisme spiritualis rasionalis (rationalist spiritualist fundamentalism) yang dibedakan dengan fundamentalisme aktivis politis (activist political fundamentalism) karena memperjuangkan Islam sebagai entitas politik dan tidak menekankan pembaharuan pemikiran keagamaan yang autentik. ${ }^{37}$

Adapun menurut Mahmud Amin al-Alim, istilah fundamentalisme secara etimologi berasal dari kata "fundamen", yang berarti dasar. Secara terminologi, berarti aliran pemikiran keagamaan yang cenderung menafsirkan teks-teks keagamaan secara rigid (kaku) dan literalis (tekstual). Menurutnya, pemikiran fundamentalisme telah kehilangan relevansinya karena zaman selalu berubah dan problematika semakin kompleks. Perlu dilakukannya penafsiran ulang terhadap teksteks keagamaan dengan mengedepankan ijtihad, membongkar teks-teks yang kaku, dan mengutamakan maslahah serta maqashid al-Syari'ah. ${ }^{38}$

\footnotetext{
${ }^{37}$ M. Said al-Asymawi, Menentang Islam Politik (Bandung: Alifya, 2004), 120.

${ }^{38}$ Abdurrahman Kasdi, "Fundamentalisme Islam Timur Tengah: Akar Teologi Kritik Wacana dan Politisasi Agama" dalam Jurnal Tashwirul Afkar, Ed. No. 13 (Jakarta: LAKPESDAM dan The Asia Foundation, 2004), 20.
} 
Adapun menurut M. Abid al-Jabiri, istilah "Islam Fundamentalis" pada awalnya dicetuskan sebagai signifier bagi gerakan Salafiyah Jamaludin al-Afghani karena bahasa Eropa tak punya istilah padanan yang tepat untuk menerjemahkan istilah "Salafiyah". ${ }^{39}$ Pendapat senada juga diungkapkan oleh Hassan Hanafì. Profesor filsafat Universitas Cairo ini mengatakan bahwa "muslim fundamentalis" merupakan istilah untuk menunjuk gerakan kebangkitan Islam, revivalisme Islam, dan gerakan/kelompok Islam kontemporer, yang sering digunakan oleh peneliti Barat dan oleh banyak pemikir. ${ }^{40}$

Menurut Ali Syuaibi, fundamentalisme, yang dalam bahasa Arabnya disebut dengan istilah ushuliyah, artinya kembali kepada al-Quran dan Sunnah. Dari pengertian ini, dapat dikatakan bahwa mayoritas umat Islam yang beriman bisa digolongkan sebagai fundamentalis (usuliyun). Mereka tidak mengamini kekerasan dan tidak mengimani terorisme karena keduanya bertentangan dengan al-Quran dan Sunnah. Oleh sebab itu, ketika istilah fundamentalisme disematkan kepada gerakan Islam politik yang seringkali diwarnai dengan aksi kekerasan dan teror, maka tidak bisa secara mutlak dikatakan sebagai gerakan agama Islam, melainkan lebih dekat kepada gerakan politik biasa. ${ }^{41}$

Dan paparan di atas, terlihat bahwa istilah "Islam Fundamentalis" telah mengalami pemutlakan, pelebaran dan penyempitan makna. Istilah ini sempat digunakan untuk merujuk pada fenomena Salafiyah al-Afghani. Istilah ini kemudian

\footnotetext{
${ }^{39}$ M. 'Abid al-Jabiri, "Darurah al-Bah 'an Niqat al-Iltiqa li Muwajahah al-Mashir al-Musyłarak" dalam Hassan Hanafi \& M 'Abid Al-Jabiri, Hiwar al-Masyriq wa al-Maghrib (Beirut: Muassasah alArabiyyah, 1990), 32-34.

${ }^{40}$ Hassan Hanafi, Aku Bagian dari Fundamentalisme Islam (Yogyakarta: Islamika, 2003), 110.

${ }^{41}$ Ali Syuaibi dan Gils Kibil, Meluruskan Radikalisme Islam (Jakarta: Pustaka Azhari, 2004), $166-$ 167.
} 
mengalami pelebaran, yaitu digunakan untuk semua gerakan revivalisme Islam. Lalu disempitkan untuk gerakan muslim radikal/ekstrim/literal/garis keras. Dari penyempitan makna inilah, yang kini sering dijadikan sebagai "relational meaning" bagi kata "Islam Fundamentalis".

\section{Karakteristik Paham Islam Fundamentalis}

Karakteristik fundamentalisme yang dilekatkan pada Islam adalah skriptualisme, yaitu keyakinan harfiah terhadap kitab suci yang merupakan firman Tuhan dan dianggap tanpa kesalahan. Dengan keyakinan itu, dikembangkanlah gagasan dasar yang menyatakan bahwa agama tertentu dipegang secara kokoh dalam bentuk literal dan bulat tanpa kompromi, pelunakan, reinterpretasi dan pengurangan. ${ }^{42}$

Banyak kelompok Islam yang menolak disebut sebagai fundamentalis, meski beberapa karakteristik yang menjadi platform gerakannya diberikan label fundamentalis, sebagaimana dalam penjelasan berikut: ${ }^{43}$

Pertama, cenderung melakukan interpretasi literal terhadap teks-teks suci agama, dan menolak pemahaman kontekstual atas teks agama karena pemahaman seperti ini dianggap akan mereduksi kesucian agama. Dari segi metodologi, pemahaman, dan penafsiran teks-teks keagamaan, kaum fundamentalis mengklaim kebenaran tunggal. Kebenaran hanya ada di dalam teks dan tidak ada kebenaran di luar teks, bahkan sebetulnya yang dimaksud adalah kebenaran hanya ada pada pemahaman mereka terhadap hal yang dianggap sebagai prinsip-prinsip agama. Tidak ada

\footnotetext{
${ }^{42}$ Azyumardi Azra, "Fenomena Fundamentalisme delam Islam" dalam Ulumul Qur' an No. 3 Vol. IV, 1993.

${ }^{43}$ Abdurrahman Kasdi, Fundamentalisme Islam Timur Tengah, 21.
} 
ruang (space) bagi pemahaman dan penafsiran lain. Tidak ada kebenaran di luar itu, baik pada agama lain, maupun dalam aliran lain atau denominasi lain dari agama yang sama. Sikap yang demikian dalam memperlakukan teks keagamaan menurut Abou el-Fadl adalah sikap otoriter. Seolah-olah upaya yang dilakukan oleh penafsir teks lalu dianggap itulah "kehendak Tuhan". Menurutnya, para tokoh agama sekarang ini tidak lagi berbicara tentang Tuhan, melainkan berbicara "atas nama Tuhan", bahkan menjadi "corong Tuhan" untuk menyampaikan pesan-pesan moral di atas bumi. Hal ini cukup berbahaya karena ketika terjadi perselingkuhan antara agama dan kekuasaan, maka yang muncul kemudian adalah otoritarianisme atau kesewenang-wenangan penguasa. ${ }^{44}$

Kedua, menolak pluralisme dan relativisme. Bagi kaum fundamentalis, pluralisme merupakan produk yang keliru dari pemahaman terhadap teks suci. Pemahaman dan sikap yang tidak selaras dengan pandangan kaum fundamentalis, yang merupakan bentuk dari relativisme keagamaan. Hal itu terutama muncul tidak hanya dari intervensi nalar terhadap teks kitab suci, tetapi juga karena perkembangan sosial kemasyarakatan yang telah lepas dari kendali agama.

Ketiga, monopoli kebenaran atas tafsir agama. Kaum fundamentalis cenderung menganggap dirinya sebagai penafsir yang paling absah atau paling benar sehingga memandang sesat kepada aliran yang tidak sepaham dengannya. Tidak bisa membedakan antara al-din (agama) dan aldini (pemikiran keagamaan) yang berbentuk tafsir. Adapun yang lebih parah adalah adanya klaim hanya tafsir dan

\footnotetext{
${ }^{44}$ Abou el-Fadl, Atas Nama Tuhan, dari Fikih Otoriter ke Fikih Otoritatif, terj. oleh R. Cecep Lukman Yasin (Jakarta: PT Serambi Ilmu Semesta, 2004), 16.
} 
pendapatnya yang paling benar. Tafsir dan pendapat orang lain/kelompok lain adalah salah. Sikap keagamaan yang seperti ini berpotensi untuk melahirkan kekerasan, dengan dalih atas nama agama, atas nama membela agama, atas nama Tuhan.

Keempat, setiap gerakan fundamentalis hampir selalu dapat dihubungkan dengan fanatisme, eksklusifisme, intoleran, radikalisme, dan militanisme. Kaum fundamentalisme selalu mengambil bentuk perlawanan yang bukannya tak sering bersifat radikal terhadap ancaman yang dipandang membahayakan eksistensi agama dalam bentuk modernitas atau modernisme, sekularisasi atau tata nilai Barat pada umumnya. Kaum fundamentalisme sebenarnya tidak serta-merta mesti memilih jalan kekerasan, namun banyaknya fundamentalis yang tidak sabar melihat penyimpangan dalam masyarakat dan melakukan tindakan kekerasan atas mereka yang dianggap bertanggung jawab. ${ }^{45}$

Sikap militan tidak jarang terlihat dengan jelas dalam gerakan fundamentalisme. Orang-orang fundamentalis merasa terpanggil, bahkan terpilih untuk meluruskan penyimpangan dalam bentuk pembelaan terhadap agama. Hal ini tampaknya sangat wajar. Pesan-pesan dasar agama sudah sangat jelas, yang harus dilakukan adalah melaksanakannya dengan segala konsekuensinya, termasuk meluruskan orang-orang yang dianggap berusaha membelokkan pesan-pesan agama. Sikap fundamen tidak terbangun dengan sendirinya. Bisa jadi kesadaran tersebut lahir karena dialektika yang berlangsung secara produktif dalam dinamika hidup yang panjang.

\footnotetext{
${ }^{45}$ Machasin, Fundamentalisme dan Terorisme, 798.
} 


\section{Latar Belakang Lahirnya Fundamentalisme dalam Islam}

Pelacakan historis gerakan fundamentalis awal dalam Islam bermula pada usaha untuk memulihkan kembali kekuatan Islam pada umumnya didorong oleh dua faktor, yang pertama: pemurnian ajaran Islam dari unsur-unsur asing yang dipandang sebagai penyebab kemunduran Islam, seperti gerakan Wahabiyah yang dipelopori oleh Muhammad bin Abd al-Wahhab di Saudi Arabia, Syah Waliyullah di India dan gerakan Sanusiyah di Afrika Utara yang dipimpin oleh Said Muhammad Sanusi dari Aljazair. Dan yang kedua: Menimba gagasan-gagasan pembaruan dan ilmu pengetahuan dari Barat. Hal ini tercermin dalam pengiriman para pelajar muslim oleh penguasa Turki dan Mesir ke negara-negara Eropa untuk menimba ilmu pengetahuan dan dilanjutkan dengan gerakan penerjemahan karya-karya Barat ke dalam bahasa mereka. Pelajar-pelajar India juga banyak yang menuntut ilmu ke Inggris.

Gerakan pembaharuan itu, dengan segera juga memasuki dunia politik, karena Islam memang tidak bisa dipisahkan dengan politik. Gagasan poiltik yang pertama kali muncul adalah gagasan Pan-Islamisme (Persatuan umat Islam Sedunia) yang pada awalnya didengungkan oleh gerakan Wahabiyah dan Sanusiyah. Namun, gagasan ini baru disuarakan dengan lantang oleh tokoh pemikir Islam terkenal, Jamaluddin al-Afghani. Al-Afghani-lah orang pertama yang menyadari sepenuhnya akan dominasi Barat dan bahayanya. Oleh karena itu, dia mengabdikan dirinya untuk memperingatkan dunia Islam akan hal tersebut dan melakukan usaha-usaha untuk pertahanan. Salah satunya adalah dengan menerapkan Islam secara fundamental. Al-Afgani juga berusaha membangkitkan semangat lokal dan nasional 
negeri-negeri Islam. Karena itu, al-Afghani dikenal sebagai Bapak Nasionalisme dalam Islam.

Semangat Pan-Islamisme yang bergelora itu mendorong Sultan Hamid II, untuk mengundang al-Afghani ke Istanbul. Gagasan ini dengan cepat mendapat sambutan hangat dari negeri-negeri Islam. Gagasan Pan-Islamisme redup setelah Turki Usmani yang bersekutu dengan Jerman kalah dalam Perang Dunia I dan kekhalifahan dihapuskan oleh Mustafa Kemal.

Paham Fundamentalis masuk ke negeri-negeri Islam seiring dengan gagasan nasionalisme yang berasal dari Barat, melalui persentuhan umat Islam dengan Barat yang menjajah mereka dan dipercepat oleh banyaknya pelajar Islam yang menuntut ilmu ke Eropa atau lembaga-lembaga pendidikan Barat yang didirikan di negeri mereka. Paham Fundamentalis ini pada mulanya banyak mendapat tantangan dan pemuka-pemuka Islam, namun akhirnya berkembang dengan cepat setelah gagasan Pan-Islamisme redup dan semakin kuatnya hegemoni Barat mencengkram negeri-negeri Islam.

Di Indonesia, gerakan fundamentalis lebih banyak dipengaruhi oleh instabilitas sosial politik dalam dan luar negeri. Sejak penjajahan Belanda sampai pada akhir masa pemerintahan Suharto, Indonesia mengalami krisis multidimensi yang parah. Demikan pula masalah Palestina dan penindasan terhadap negara-negara Islam yang lain, memberi andil yang besar terhadap perkembangan Islam fundamental di Indonesia. Era reformasi, kebebasan berpendapat dan berkelompok, merupakan momen emas bagi kaum fundamentalis untuk menyuarakan pendapatnya, menawarkan solusi mengatasi krisis multidimensi yang terjadi di Indonesia. 
Dari latar belakang ini, tidak heran jika banyak tudingan yang mengatakan bahwa gerakan fundamentalisme Islam merupakan bagian dari politisasi Islam. Sebagaimana dijelaskan Bassam Tibbi, fundamentalisme Islam memiliki agenda politisasi Islam. Islam dijadikan sebagai ideologi politik alternatif. ${ }^{46}$

\section{E. Gerakan Islam Fundamentalis di Indonesia}

Munculnya gerakan keagamaan yang berkarakter fundamentalis merupakan fenomena penting yang turut mewarnai citra Islam kontemporer di Indonesia. Istilah Islam fundamentalis sebagai sebuah kesatuan dan berbagai fenomena sosial keagamaan dan kelompok-kelompok muslim yang sedemikian kompleks. Hal ini disebabkan definisi yang dibuat tidak sepenuhnya mampu mendeskripsikan fenomena beragam atas gerakan-gerakan keagamaan yang muncul di Indonesia. Selain itu, dalam beberapa literatur, istilah yang digunakan untuk menggambarkan fenomena kontemporer "fundamentalisme Islam" tidaklah seragam. Istilah Islam fundamentalis seringkali dipakai secara overlapping dengan istilah Islam radikal atau Islam revitalis.

Berdasarkan karakteristik-karakteristik yang menjadi platform gerakan fundamentalis di Indonesia, terdapat beberapa kelompok yang diasumsikan sebagai kelompok Islam fundamentalis. Di antaranya adalah Front Pembela Islam (FPI), Hizbut Tahrir Indonesia (TITI), Forum Komunikasi Ahlussunnah Wal Jamaah (FKAWJ), Majelis Mujahidin Indonesia (MMI), dan Laskar Jihad, Partai Keadilan

\footnotetext{
46 Bassam Tibbi, "Kaum Fundamentalis Jadikan Islam sebagai Ideologi Politik" dalam Jurnal Tashwirul Afkar, Ed. No. 13 (Jakarta: LAKPESDAM dan The Asia Foundation, 2002), 118.
} 
Sejahtera (PKS), Partai Bulan Bintang (PBB), Muhammadiyah, dan Wahdah Islamiyah. ${ }^{47}$

Dengan meminjam terminologi Shireen T Hunter, dapat diidentifikasi landasan ideologis yang dijumpai dalam gerakan-gerakan Islam fundamenatlis baik di Indonesia maupun di belahan dunia lain, yaitu:

Pertama, konsep al-din wa al-daulah (agama dan negara). Dalam konsep ini, Islam dipahami sebagai sistem hidup total, yang secara universal dapat diterapkan pada semua keadaan, waktu dan tempat. Pemisahan antara agama (al-din) dan negara (daulah) tidak dapat diterima oleh kelompok fundamentalis sehingga agama dan negara dipahami secara integralistik.

Kedua, kembali kepada al-Quran dan Sunnah. Dalam konsepsi ini, umat Islam diperintahkan untuk kembali kepada akar-akar Islam awal dan praktik Nabi sallallahu 'alaihi wasallam yang puritan dalam mencari keaslian (otentisitas) dan pembaruan secara skriptual dan totalistik.

Ketiga, puritanisme dan keadilan sosial. Nilai-nilai dan budaya Barat diambil sebahagiannya, dan yang lainnya ditolak jika tidak sesuai dengan ajaran Islam. Oleh karena itu, media massa diupayakan untuk menyebarkan nilai-nilai dan praktik Islam yang otentik ketimbang menyebarkan pengaruh-pengaruh budaya asing yang sekuler. Pemahaman ini menyaratkan adanya penegakan keadilan sosial ekonomi sehingga doktrin tentang zakat sangat ditekankan. Karena dalam hubungannya dengan kebijakan negara, maka dianggap dapat memajukan kesejahteraan sosial dan mampu memperbaiki kesenjangan kelas di kalangan umat.

\footnotetext{
${ }^{47}$ Jamhari dan Jajang Jahroni, Gerakan Salafi, 10.
} 
Keempat, berpegang teguh pada kedaulatan syariat Islam dan penegakannya dalam kehidupan. Tujuan ini bisa dicapai dengan membangun tatanan Islam (Nizâm al-islâm) yang memposisikan syariat sebagai Undang-Undang tertinggi. Dan pemahaman ini, maka agenda formalisasi syariat Islam menjadi entry point bagi terbentuknya negara Islam sehingga syariat Islam benar-benar dapat diperlakukan dalam hukum positif, baik hukum perdata seperti perkawinan, perceraian, waris, maupun hukum jinayat seperti potong tangan dan lain sebagainya.

Kelima, menempatkan jihad sebagai instrumen gerakan. Umat Islam diperintahkan untuk membangun masyarakat ideal sebagaimana telah digariskan dan sesuai dengan syariat Islam. Oleb sebab itu, diperlukan adanya upaya untuk menghancurkan kehidupan jahiliyah dan menaklukkan kekuasan-kekuasaan duniawi melalui jihad. Jihad tidak dilakukan dalam pengertian defensif semata. tapi memuat tujuan jihad untuk menaklukkan semua hambatan penyiaran Islam ke seluruh dunia, yang meliputi negara, sistem sosial dan tradisi-tradisi asing.

Keenam, perlawanan terhadap Barat yang hegemonik dan menentang keterlibatan mendalam dan pihak Barat untuk urusan dalam negara Islam, seperti yang terjadi di Irak, Libya, Bosnia, Afghanistan dan Palestina. Mereka merasa harus mendeklarasikan perlawanannya terhadap Barat karena umat Islam sudah diperlakukan dengan tidak adil, baik secara politik, ekonomi, maupun budaya. Dominasi Barat atas negara Islam tidak dalam kapasitas saling bekerjasama 
melainkan memojokkan dan memusuhi, Pada gilirannya, ketidakadilan Barat dilawan dengan aksi-aksi kekerasan di berbagai negara, termasuk Indonesia. ${ }^{48}$

Ideologi-ideologi inilah yang menyatukan gerakan-gerakan Islam di berbagai negara termasuk Indonesia. Dan hanya dibedakan oleh bentuk artikulasi gerakan. Dalam hal ini, mereka sangat tergantung pada problem yang dihadapi di Negara masing-masing. Di Indonesia misalnya, antara Hizbut Tahrir Indonesia, Majelis Mujahidin Indonesia dan Front Pembela Islam (FPI) memiliki kesamaan ideologi, namun cara menerjemahkan ideologi dan praktik gerakannya satu sama lain memiliki perbedaan. Demikan pula dengan Muhammadiyah, Wahdah Islamiyah, PKS dan Partai Bulan Bintang (PBB).

\section{F. Dakwah dan Sikap Terhadap Islam Fundamental}

Dilihat dari substansinya, pandangan, sikap dan keyakinan keagamaan kaum fundamentalis tidak keluar dari Islam. Mereka termasuk orang muslim dan mukmin yang taat, bahkan dapat dikatakan bahwa mereka sangat berpegang teguh pada ajaran Islam serta ingin memperjuangkannya dengan segala upaya dan kemampuan yang dimiliki agar ajaran Islam, yang mereka pahami dengan benar dapat dilaksanakan oleh seluruh umat manusia tanpa kecuali. Dengan demikian, kehadiran fundamentalisme tidak mesti direspon secara searah dan dengan pandangan negatif. Menurut Machasin, orang dapat mengambil pelajaran berharga dari sikap dan kegiatan kaum fundamentalis. Anggota-anggota mereka terlihat mempunyai kesetiaan yang kuat pada prinsip yang dianut. Kesetiaan semacam itu

\footnotetext{
${ }^{48}$ Mukhlas Syarkun dan W Ghorara, "Dunia Islam dalam Benturan Kepentingan dan Peradaban" dalam Negara Tuhan; The Thematic Encyclopedia (Jakarta: SR Ins Publishing, 2004), 491 -493.
} 
sangat diperlukan dalam kehidupan ini. Apa yang dapat dilakukan dalam mengubah keadaan yang tidak adil, tidak aman, tidak memberikan kemungkinan bagi setiap warga masyarakat untuk berpartisipasi dan seterusnya kalau orang tidak setia kepada prinsip?

Dalam hal ini, semua itu hendaknya dijalankan dengan cara yang santun dan tidak menakutkan orang lain. Dari militansi yang terlihat dalam kelompok fundamentalis, dapat diambil pelajaran mengenai semangat kerja, dan kemauan untuk bekerja keras. Kemalasan dan kelemahan semangat merupakan penyakit yang menimpa kaum muslimin negeri ini untuk waktu yang cukup lama. Fundamentalisme mengajak manusia untuk berbuat, dan untuk tidak diam saja karena pilihan lainnya adalah perubahan ke arah yang lebih buruk.

Eksklusivitas kaum fundamentalis dapat dipakai untuk membangun kerja tim dalam kehidupan masyarakat Islam. Ekslusivitas memang jelek dan kadang-kadang menakutkan, namun pada kelompok-kelompok eksklusif seperti yang ditunjukkan fundamentalisme Islam terlihat dengan jelas solidaritas sesama anggota. Sebagai sebuah kelompok, mereka memiliki ikatan solidaritas yang cukup tinggi, kokoh, militan dan rela menerima resiko dari sebuah perjuangan. ${ }^{49}$

Hal ini tidak untuk mengatakan bahwa fundamentalisme Islam mesti didukung, Justru dakwah bi al hikmah harus diberikan kepada kelompok ini, untuk meluruskan sebagian (sekelompok) dari mereka telah keluar dari rambu-rambu amar makruf nahi mungkar. Nasehat dan dialog harus terus dijalin kepada mereka agar memperbaiki kekurangan-kekurangan yang berupa:

\footnotetext{
${ }^{49}$ Machasin, Fundamesitalisme dan Terorisme, h. 817-818.
} 
Pertama, dari segi keyakinan keagamaannya, mereka bersikap rigid dan literalis. Kaum fundamentalis lebih menekankan simbol-simbol keagamaan daripada substansinya. Mereka menganggap bahwa doktrin agama telah mengatur segalagalanya. Agama dinilainya sebagai sistem yang lengkap dan mencakup pelbagai sub-sistem di dalamnya. Pandangan seperti ini bisa dijumpai rujukannya pada Abu al-A'la al-Maududi dan Sayyid Qutb. Mereka memiliki pandangan keagamaan yang berbeda dengan kaum modernis, yang pada umumnya kurang mementingkan soal istilah atau simbol-simbol keagamaan yang bercorak distinktif. Bagi kalangan modernis, yang penting adalah agar prinsip-prinsip, cita-cita dan roh Islam dapat menjiwai kehidupan masyarakat dan negara, bukan mengutamakan simbol, sebagaimana yang dipegang teguh kaum fundamentalis.

Kedua, kekurangan mereka juga terletak pada sikap dan pandangannya yang eksklusif, yaitu pandangan yang bertolak dari keyakinan bahwa pandangan dan keyakinan merekalah yang paling benar. Sementara itu, sikap dan pandangan orang lain yang tidak sejalan dengan mereka dianggap salah. Sebagai akibat, dari sikap dan pandangan yang demikian, mereka cenderung tertutup dan tidak mau menerima pandangan dan sikap orang lain yang berbeda tidak terbuka dan tidak ada jalan baginya untuk berdialog.

Ketiga, dari segi budaya dan sosial dalam menyikapi berbagai produk budaya modern yang bersifat kultural seperti pakaian, alat-alat keperluan kebersihan dan lain sebagainya yang bersifat konservatif. Kehidupan mereka terkesan kolot, kuno bahkan cenderung nyeleneh. 
Keempat, dari segi bentuk dan sifat gerakannya. Mereka cenderung memaksakan kehendak dengan menggunakan berbagai cara termasuk cara-cara kekerasan. Dengan sikapnya yang demikian, mereka seringkali dianggap sebagai kelompok gerakan radikal, fanatik dan sebagainya. ${ }^{50}$

\section{G. Penutup}

Istilah fundamentalis asalnya dari Kristen di Amerika. Istilah ini pun pernah digunakan untuk merujuk pada fenomena Salafiyah Wahabiyah, Sanusiyah dan Salafiyah al-Afghani. Istilah ini kemudian mengalami pelebaran, yaitu digunakan untuk semua gerakan revivalisme Islam. Lalu disempitkan untuk gerakan muslim radikal/ekstrim/literal/garis keras. Dari penyempitan makna inilah, yang kini sering dijadikan sebagai "relational meaning" bagi kata "Islam Fundamentalis". Karakteristik fundamentalisme yang berasal dari Kristen lain dilekatkan pada Islam adalah skriptualisme, yaitu keyakinan harfiah terhadap kitab suci yang merupakan firman Tuhan dan dianggap tanpa kesalahan. Dengan keyakinan itu, dikembangkanlah gagasan dasar yang menyatakan bahwa agama tertentu dipegang secara kokoh dalam bentuk literal dan bulat tanpa kompromi, pelunakan, reinterpretasi dan pengurangan. Latar belakang timbulnya gerakan fundamentalis dalam Islam adalah: permurnian ajaran Islam dari unsur-unsur asing yang dipandang sebagai penyebab kemunduran Islam, dan menimba gagasan-gagasan pembaruan dan ilmu pengetahuan dari Barat. Gerakan fundamentalis Islam di Indonesia lebih banyak dipengaruhi oleh instabilitas sosial politik dalam dan luar

\footnotetext{
${ }^{50}$ Abudin Nata, Peta Keragaman Pemikiran Islam di Indonesia (Jakarta: PT Raja GTafindo Persada, 1992), 25-26.
} 
negeri, mulai jaman penjajahan Belanda sampai akhir masa pemerintahan Suharto, serta masalah global yang dialami dunia Islam. Oleh karena itu, dakwah bi al hikmah, nasehat, dan dialog harus terus dijalin dengan kelompok fundamental Islam. 


\section{Daftar Pustaka}

Sbou el-Fadl, Atas Nama Tuhan, Dari Fikih Oteriter ke Fikih Otoritatif. Teri. R. Cecep Lukman Yasin. Jakarta: PT. Serambi Ilmu Semesta, 2004.

Al-asymawi, M. Said, Menentang Islam Politik. Bandung:Alifya, 2004.

Azra, Azyumardi, "Fenomena Fundamentalise dalam Islam" dalam Ulumul Qur'an No. 3 Vol. IV, 1993.

Denny, Fredrick M., Islam and The Muslim Community. New York: Harper \& Row, 1987.

Graudy, R., Islam Fundamentalis dan Fundamentalis lainnya. Teri. Afif Muhammad. Bandung: Penerbit Pustaka, 1983.

Hanafi, Hassan, Aku Bagian dari Fundamentalism Islam. Yogyakarta: Islamika, 2003.

AL-Jabiri, M.'Abid."Darurah al-Bahs'an Niqăt al-Iltikā li Muwăjahah al-Mashir alMusytarak" dalam Hassan Hanafi \& M. 'Abid Al-Jabiri, Hiwar al-Masyriq wa al-Magrib. Beitut: Muassasah al-Arabiyyah, 1990.

Jamhari dan Jajang Jahroni, Gerakan Salafi Radikal di Indonesia. Jakarta: Raja Grafindo Persada, 2014.

Kamus Besar Bahasa Indoensia. Cet. III; Jakarta: Balai Pustaka, 1990.

Kasdi, Abdurrahman, "Fundamentalisme Islam Rimur Tengah: Akar Teologi, Kritik Wacana dan Politisasi Agama" dalam Jurnal Tashwiurl Afkar, Ed. No. 13. Jarta: LAKPESDAM dan The Asia Foundation, 2004.

Machasin, "Fundamentalisme dan Terorisme", dalam Negara Tuhan; The Thematic Encyclopedia. Jakarta: SR Ins Publising, 2004.

Nata, Abudin, Peta Keragaman Pemikiran Islam di Indonesia. Jakarta: PT. Raja Grafindo Persada, 1992. 
Al-salabi, Ali Muhammad, Al-Aaulah al-Usmaniyyah; 'Awāmil al-Nahdah wa Asbăb al-sukŭt. Terj. Samson Rahman, Bangkit dan Runtuhnya Kalifah Utsmaniyah. Cet. IV; Jakarta: Pustaka al-Kautsar, 2011.

Syarkun. Mukhlas dan W Gorara, "Dunia Islam Dalam benturan Kepentingan dan Peradaban" dalam Negara Tuhan; The Thematic Wncylopedia. Jakarta: SR Ins Publising 2004.

Syuaibi, Ali dan Gils Kibil, Meluruskan Radikalisme Islam. Jakarta: Pustaka Azhari, 2004.

Tibbi, Bassam, "Kaum Fundamentalis Jadikan Islam Sebagai Ideologi Politik" dalam Jurnal Tashwirul Afkar, Ed. No. 13, Jakarta: LAKPESDAM dan The Asia Fundation, 2002.

Wuthnow, Robert, Meaning and Moral Order. California: The University Of California Press, 1987. 


\section{Petunjuk Penulisan}

Tasâmuh menerima tulisan dalam bentuk artikel dan laporan penelitian, baik yang menggunakan bahasa Indonesia, Inggris, maupun Arab, dengan ketentuan sebagai berikut:

1. Tulisan tersebut belum pernah diterbitkan atau dipublikasikan dalam suatu jurnal berkala atau buku.

2. Topik tulisan berkisar pada kajian-kajian yang berkaitan dengan ilmu dakwah dan Komunikasi.

3. Judul tulisan maksimal 14 kata.

4. Semua tulisan harus menyertakan abstrak (100-150 kata) dan kata kunci (3-7 kata).

5. Jumlah halaman antara 15-20 nomor halaman dengan ukuran kwarto spasi ganda dengan menggunakan jenis huruf Futura $\mathrm{Lt} \mathrm{B} \dagger$ dan besar hurup 12 pt.

6. Setiap kata Arab yang belum resmi terbakukan dalam bahasa Indonesia ditulis mengikuti pedoman transliterasi yang ditetapkan dan cara penulisannya dimiringkan (italic), hal ini juga berlaku untuk kata-kata asing yang lain (seperti bahasa Inggris dan bahasa Daerah) dan cara penulisannya dimiringkan (italic),

7. Transliterasi tidak berlaku untuk nama orang, tempat, institusi, dan sejenisnya.

8. Penulis menyerahkan file beserta print out naskahnya.

9. Semua tulisan menggunakan referensi model footnote dengan teknik penulisan sebagai berikut: Nama Penulis, Judul Buku Yang Ditulis Miring (Kota Penerbit: Nama Penerbit, Tahun Terbit), Nomor Halaman. Sebagai contoh:

a. Buku atau Kitab:

- John Lewis Coser, The Function of Social Conflict (New York: Free Press, 1969), 125. 
- Sofian Effendi, Membangun Martabat Manusia Dalam Perspektif Islam (Yogakarta: UGM Press, 2005), 24.

- Ibnu Jarir al-Thabari, Jami' al-Bayan, Jilid 9 (Beirut: Dar alKutub Ilmiyah, 1992), 67.

b. Buku Terjemahan:

David Hill, Pengembangan dan Pemberdayaan Masyarakat, ter. Adam Hulaimi, Jilid 2 (Jakarta: Pustaka Pelajar, 1997), 127.

c. Artikel dalam Buku atau Ensiklopedi:

- Nurcholis Majid, "Cendekiawan dan Penguatan Civil Society di Indonesia" dalam Peran Cendekiawan Muslim Dalam Menegakkan Hak Politik Civil Society, ed. Tim Editor Masika (Jogjakarta: Bintang Budaya, 1996), 124.

- D.S. Adam, "Theology," Encyclopedia of Religion and Ethics, ed. James Hastings, Jilid 4 (New York: Charles Scribner's Sons, tt), 293.

d. Artikel dalam Jurnal:

Faisal Ismail, "On Developing Liberation Theology in Islam," dalam Jurnal Gazwatul Fikri, Vol. 9 No. 2 (Yogyakarta: Fakultas Dakwah UIN Sunan Kalijaga, Desember 1999), 165.

e. Artikel dalam Media Massa:

Fawaizul Umam, "Quo Vadis Kebebasan Beragama di Indonesia", dalam Koran KOMPAS, Edisi 30 Maret 2001, 4.

f. Kitab Suci:

QS. al-Qashash (28): 5. Perjanjian Baru, Yoh ( 20): 31.

g. Bila mengutip ulang referensi yang sama secara berurut, maka cukup tulis: Ibid. Jika halamannya berbeda, cukup tambahkan nomor halamannya: Ibid., 14.

h. Bila referensi terkutip ulang berselang oleh satu atau lebih referensi berbeda, maka cukup tulis last name pengarang berikut satu kata awal judul dari referensi dimaksud. Misalnya, Zahrah, Ushûl..., 35. 
10. Selain mencantumkan footnote, penulis juga harus mencantumkan DAFTAR PUSTAKA dengan aturan penulisan diurutkan secara alfabetis. Nama penulis diketik dengan mendahulukan nama marga atau nama akhir jika nama penulis terdiri dari 2 kata atau lebih, judul buku atau nama jurnal maupun nama media massa ditulis miring (Kota Penerbit: Lembaga Penerbit, Tahun Terbit) tanpa diakhiri tanda titik.

Contoh:

a. Buku: Nasution, Harun, Perkembangan Pemikiran Cendikiawan Muslim Indonesia (Jakarta: Dunia Ilmu, 1998)

b. Jurnal: Ismail, Faisal, "On Developing Liberation Theology in Islam," dalam Jurnal Gazwatul Fikri, Vol. 9 No.2 (Yogyakarta: Fakultas Dakwah UIN Sunan Kalijaga, Desember 1999)

c. Media massa: Umam, Fawaizul, "Quo Vadis Kebebasan Beragama di Indonesia", dalam Koran KOMPAS, Edisi 30 Maret 2001

d. Makalah: Akbar, Muhammad, "Membangun Paradigma Baru Fakultas Dakwah", dalam Makalah Seminar Pengembangan Fakultas Dakwah di Indonesia, Mataram, 3 Maret 2004 